\title{
Sequence \& Access, Storytelling \& Archive in Mobile Augmented Reality
}

\author{
Gunnar Liestøl, University of Oslo \\ Department of Media \& Communication \\ Oslo, Norway \\ gunnar.liestol@media.uio.no
}

\begin{abstract}
When digitally reconstructing and displaying sequences of historical events in situ, a paradox may emerge: The sequence of actions might often benefit from in-depth information about historical context of various types. However, the moment the user embarks on a contextual digression to seek a better understanding, the sequence itself is abandoned and/or fragmented. How may we best combine sequence and access, storytelling and in-depth exploration to the benefit of rich locative cultural heritage experiences? In this paper we consult narrative theory to find a design and to implement the solution in three different reconstructions of historical events on location. These are selected from antiquity and World War II. We present the challenges and solutions so far, as well as feedback from visitors testing the situated simulation applications on location.
\end{abstract}

Keywords-Storytelling, narrative theory, situated simulation, sitsim, sequence-access paradox, indirect augmented reality, mobile augmented reality, augmented reality, World War II, Omaha Beach, Acropolis.

\section{INTRODUCTION AND BACKGROUND}

The primary purpose of this project is to experiment with situated simulation, or Indirect Augmented Reality [1], of historical actions and events where short, complex sequences are central, and where in addition it is possible to access relevant and detailed background information without fragmenting and weakening the experience of the story sequence itself. This challenging relationship between story and archive we may name the 'sequence-access paradox'.

The dramatic boost in graphics performance now taking place due to improved hardware and new software solutions for 3D handling has allowed simulations of historic sites in situ to be no longer limited to static environments (buildings, landscapes and monuments), but - increasingly - to be directed towards visualization of complex and spectacular events involving compound movements and activities of various kinds - including humanoid characters in motion.

In a situated simulation ( sitsim) there is an approximate identity between the user's visual perception of the real physical environment and the user's visual perspective into a 3D graphics environment as it is represented on the screen. The relative congruity between the real and the virtual perspectives is obtained by letting the camera position and movement in the 3D environment be conditioned by the positioning and orientation hardware. As the user moves in real space the perspective inside the 3D graphical environment changes accordingly. With a situated simulation the mobile phone or tablet serves as a 'window' to the past. Thus historical events can be recreated digitally on the site where it actually took place [2]. For more information about the project, see SitsimLab, University of Oslo (www.sitsim.no).

Solving the sequence-access paradox is of general interest to anyone working with reconstructions and simulations of historical events in digital and interactive environments, whether on or off location. As our capacity to simulate historical events in all its complexity increases, we will also want to enrich the reconstruction of the event itself with background and in-depth information and knowledge of various kinds: political, cultural, historical, technical, personal and more. In the following we will discuss three separate locative historical reconstructions and the experience we have derived from them: the sinking of the heavy cruiser Blücher in the Oslo Fjord at the beginning of World War II, the ancient Panathenaia Procession on the Acropolis in Athens, and the DDay landing on Omaha Beach in Normandy. We will also discuss the types of testing and evaluation we have conducted so far and the feedback we have received.

\section{SINKING BLÜCHER - A BATTLE AND ITS DRAMATIC STRUCTURE}

At 4:21 AM on the morning of the 9th of April 1940 the two $28 \mathrm{~cm}$ Krupp guns at Oscarsborg Fortress opened fire at the German cruiser Blücher, then located just outside Drøbak harbour. The officer in charge of the fortress had been informed that enemy warships were heading towards Oslo and that they had been involved in acts of war against Norway further out in the Oslo Fjord. Immediately after the two shots from Oscarsborg were fired, the Kopås and Husvik batteries on the Eastern side of the strait followed up with further rounds, both against Blücher and the cruiser Lützow, the second ship in the attack force. Blücher tried to answer the bombardment, but with a severe fire amidships the cruiser continued with great difficulty in manoeuvring the narrow strait. When it passed the torpedo station on Northern Kaholmen 10 minutes later, two underwater projectiles were launched, both hitting. Blücher loses further momentum, begins to take in water and increasingly tilts to the side. The crew tries to extinguish the fire, but at 5.30 AM it has reached the ammunition room, and causes a huge explosion. At 06.22 Blücher sinks near the islets 
Askholmene and ends up upside down on the bottom of the Fjord at a depth of 90 meters - where the wreck still resides. The majority of the ship's crew and troops were taken to safety to the nearby islets or the mainland on the Eastern side of the fjord. The number of dead and missing is uncertain, but it involved at least 300 individuals [3].

The drama in the Drøbak strait unfolds over a distance of a few kilometres and within two hours (approximately the same length of time as a feature film), and contains all the three elements of a classical drama as derived from Aristotle's poetics: the unity of action, time and place. The events have been retold numerous times and in all conceivable media and modalities, from physical models and authentic photographs in the museum at Oscarsborg fortress to documentary books and films. With the development of Mobile Augmented Reality and situated simulations we have new instruments to recreate such events for use in communication and learning on location.

However, for such simulations to work optimally the story and its many modalities must be processed and mediated in the best possible way. Situated simulation with mobile phones and tablets is still an immature form of storytelling where conventions and genre forms are only beginning to emerge. It is exploring the potential of this means of expression, especially with regard to narrative, which is the primary purpose of these experiments.

\section{NARRATIVE THEORY AND CRITICAL CONSTRUCTION IN Digital HeRitage: THE BlÜCHER PROTOTYPE.}

When adapting the story material to the sitsim indirect augmented reality platform, we have used the narrative theory of Gerard Genette as a starting point. Genette [4] formulates a number of categories for how story (the story told) and discourse (the telling of the story) relate to each other. A film can last for 90 minutes (discourse time) while the story told, its actions and events, may extend over many years (story time). It is in particular the categories 'scene', 'ellipsis' and 'summary' which are relevant in our context. A movie reproducing a story without time gaps (ellipses) is 'scenic', that is the story time and the discourse time are identical when it comes to duration. While 'summary' marks a variation where discourse time is shorter than story time, as in for example fast forward film.

If our simulation of the battle in the Drøbak strait was to be reconstructed in 'scenic' mode the visitor will experience long periods during the two hours of the event when very little happens, for example, almost 60 minutes goes by from the last torpedo hit to the big explosion in the ammunition storage room. During this period the 'only' thing that happens is that Blücher moves slowly northward and the crew tries desperately to extinguish the fire. This type of repetitive and monotonous action is of course both dramatic and important, especially for the people involved, but as a learning and experience context representing the exact duration, has limited value, neither in the simulation dramaturgy nor for the visitor who is exploring/using the application. Thus, we need ellipses and summary to increase the efficiency of the story sequence. The same narrative technique is constantly used in other storytelling media, in particular literature and film.
With digital technology it is possible to manipulate and exploit the information and the story material in different ways than in traditional analogue media. As a consequence we have, in this design organized the sequence in three scenic episodes or acts, leaving less important portions out using ellipsis (omission) and/or summary (summarily rendering/fast forward) to tighten the dramatic structure of both the story and the discourse of the simulation:

1. Scene spans the period from immediately before Oscarsborg opens fire and until the last torpedo hits (about 1215 min duration).

2. Scene comprises the large explosion in the ammunition room (about 5 min duration), and the

3. Scene depicts Blücher's last minutes afloat as the wrecked ship succumb followed by a large explosion on the surface (about 5-10 $\mathrm{min}$ ).

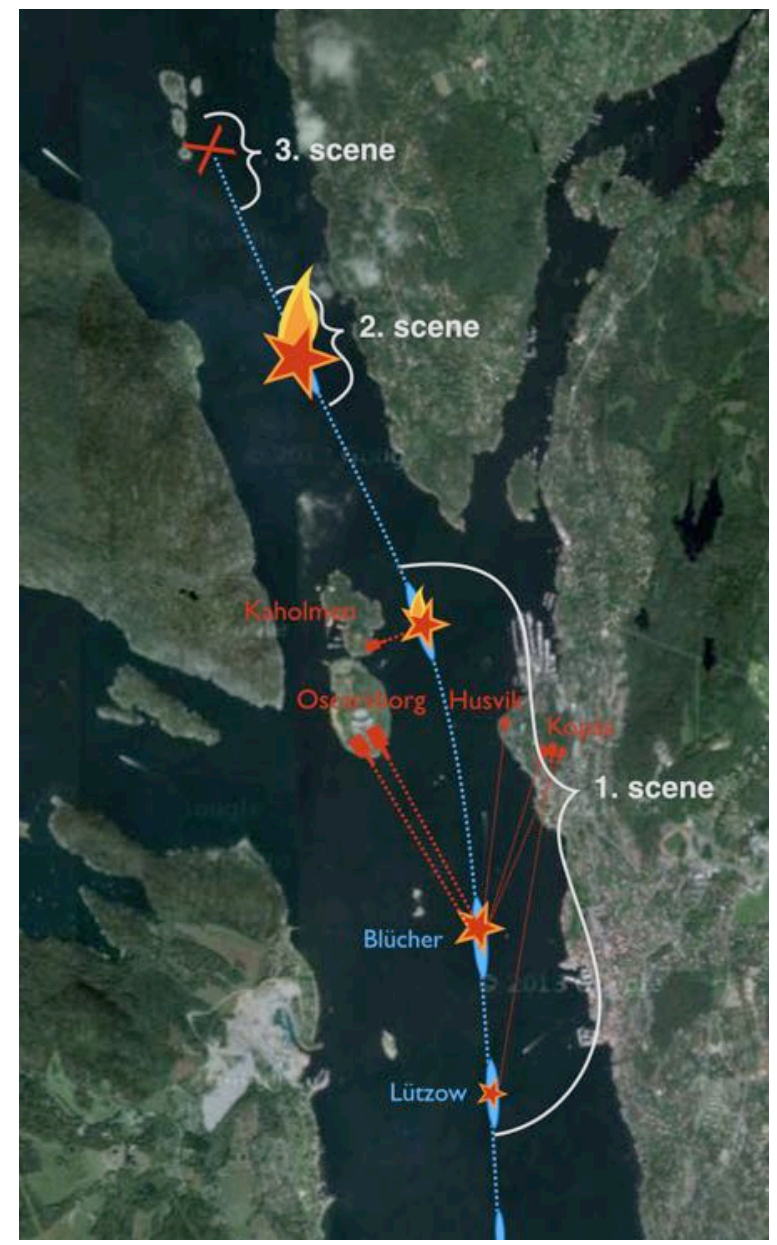

Fig. 1. Map showing how the sequence of actions and events is divided into three scenes intersected by ellipses and summary in between. Visitors to the area are then positioned on any location in and around the strait and thus explore and study the historic battle from different positions and with free camera movement. 
In all the scenes the user may apply different 'views' [5], meaning that one can override the virtual camera so that it is no longer providing the same perspective as the user has in the real physical environment. In this way, it will be possible to send the virtual camera down under water observing the Blücher wreck on the sea bed, or position the camera in one mast of the ship and observe the events from there while we physically find ourselves in the Drøbak harbour. Otherwise, the application may be used in normal 'view' wherever possible: on board the ferry to Oscarsborg Fortress or in a private boat 'following' Blücher's course.

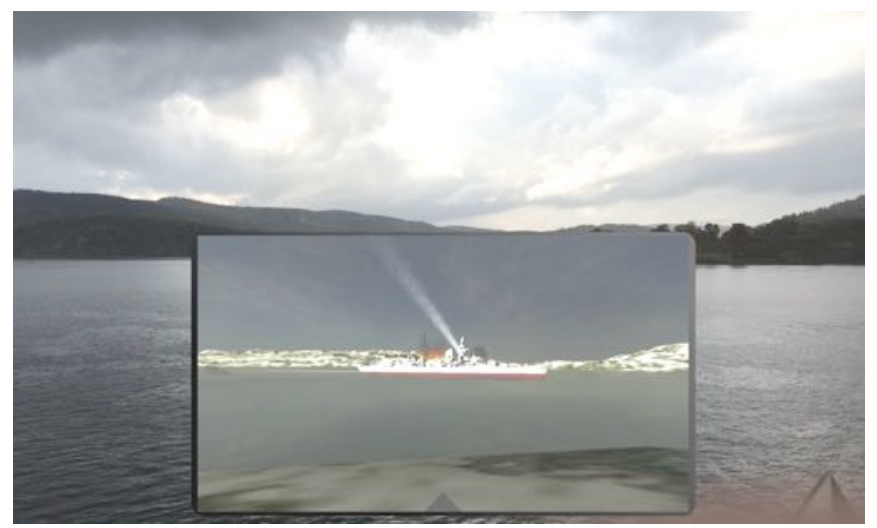

Fig. 2. A snapshot taken with the app on location with both the virtual and the physical camera creating a now/then image montage. One can observe that Blücher has already received several hits and the flames are growing. The cruiser has just received a hit from the Husvik battery positioned behind the user.

\section{The STORY SEQUENCE AND IN-DEPTH DIGRESSION}

In such temporally based retellings of historical events the 'sequence-access paradox' frequently presents itself, when in the middle of the sequence we often experience the need to leave the story for a while in order to access additional information. Such a digression may again enrich the experience of the story sequence. However, in dynamic (temporal) media we then have a problem: the moment we leave the flow of the narrative it continues without our presence and important story elements may be lost to us. In traditional media we have few solutions to this problem. In a classroom situation the teacher may be interrupted by a question and respond to it by providing an explanatory digression, and in the course of this action make the movement in and out of the story as smooth and motivated as possible. In the film and TV traditions this is not the case, we lack the conventions for such 'footnotes' (or hypertextual) diversions.

In the Blücher sitsim prototype we attempted to solve this problem by focusing on one of Genette's categories in particular: 'pause'. A 'pause' is constituted by a relationship between story time and discourse time where a stretch of time at the level of discourse has no temporal extension at the level of story (actions and events). In film an example would be the freeze frame and time-slized photography. In storytelling by means of digital media we may avoid this by controlling the unfolding of the story and its discourse. But how should we implement this control?

In the Blücher prototype we used Genette's concept of 'pause', not only as an analytical tool, but as a rule for construction, as a guide for creating a design that makes the user control the relationship between storytelling on the one hand and digressions into in-depth information for improving the quality of the story on the other, and thus do away with or abolish the inherent paradoxical nature of the sequence-access relationship.

In the Blücher prototype the structure of this implementation was the following: If the user, during the course of the battle for example, wants to know more about the artillery on board the ship and its capacity to match the firing power at the Oscarsborg Fortress one may activate the 'Explore Blücher' button in the global menu. When activated, the virtual camera is moved to the present position of Blücher and stops close to midships. As the camera 'ease in' to its position the temporal sequence of the events (story time) slows down and comes to a halt. In that position, and when story time freezes, the virtual camera can be moved towards the stern and towards the fore of the ship. Various objects are highlighted, indicating hotspots and available in-depth information. When touching the marked or highlighted main battery, a pop-up window is displayed providing introductory information and a link to indepth descriptions in a database online, in this case Wikipedia (which often has good articles on World War II topics).

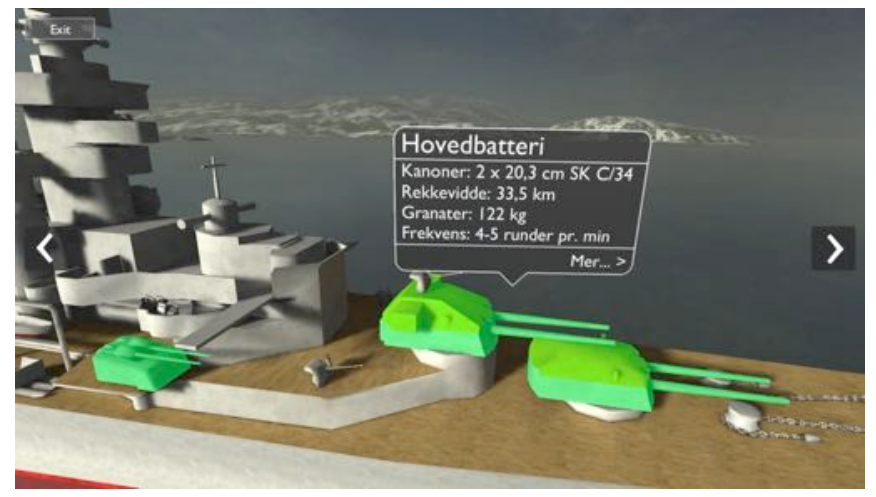

Fig. 3. A screen shot from the Blücher sitsim prototype. The 'Explore Blücher" function is activated and one of the main batteries astern has been activated and shows the pop-up window with general introductory information about the artillery including a link ('Mer... > ') to online resources for further in-depth exploration.

This prototype was the first one to introduce a solution to the sequence-access paradox, and testing on location was limited to project participants, not real visitors. The implementation was intuitive and easy to understand, and demonstrated a path towards a solution to the challenge. However, we wanted to test other approaches to linking contextual information to the environment. Using hotspots as highlighting 3D objects and elements was cumbersome and involved time-consuming preparations and was not optimal for 
any type of object. In addition, we would also require means to annotate not only objects but also positions and places/perspectives in the reconstructed environment. In the subsequent prototype we thus decided to return to a solution from previous productions: the spatially positioned hypertext link [2].

\section{The Panathenaia Procession: Spatial Hypertext as ACCESS AND ANNOTATION POINTS IN A PAUSED SCENE.}

In all the sitsim experiments and published applications prior to the Blücher prototype we employed positioned hypertext links inside the reconstructed environment for access to various kinds of augmentation (written documents, audio narration, 3D-animations, online resources etc.) [2]. For decades 'spatial hypertext' has been a well established concept in hypertext and hypermedia research. It emerged as a suitable metaphor for navigational purposes and 2D/3D mapping of node-link structures in hypertext networks $[6,7]$. Augmented reality research has also seen use of hypertext links or labels to annotate aspects of 3D-objects and environments [8].

The Panathenaia procession was part of a ceremony in honour of the Goddess Athena and included a large sacrifice at the Altar of Athena on the Acropolis hill, and next to the Parthenon, where the inner Ionic frieze also depicts scenes from the procession [9]. If the frieze can be used as a blueprint indicating the order of the procession, it included a large number of oxen and sheep that were led to the Altar, women carrying incense burners and wine jars, and men playing on string instruments and flutes.

To inform the user of the nature of the procession we included an alternative, a more generic version of the pause-toaccess function. Pausing the sequence and thus halting time and all animation in the scene is achieved by simply touching the screen. As animation and thus time is on hold, all positioned hypertext links are made visible and can be activated by touch. These operations can best be demonstrated in stills photos of a user-sequence recorded on location (see figures 4-6):

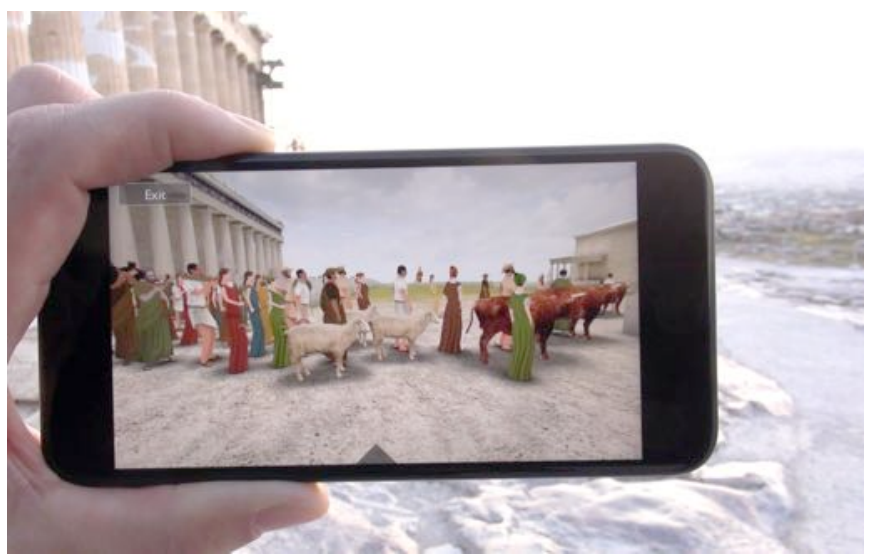

Fig. 4. Reconstruction of the Panathenaia Procession based on elements from the Parthenon Frieze in sequence mode. Note the alignment between the real Parthenon to the left in the background of the photo and the digital reconstruction to the left on the screen.

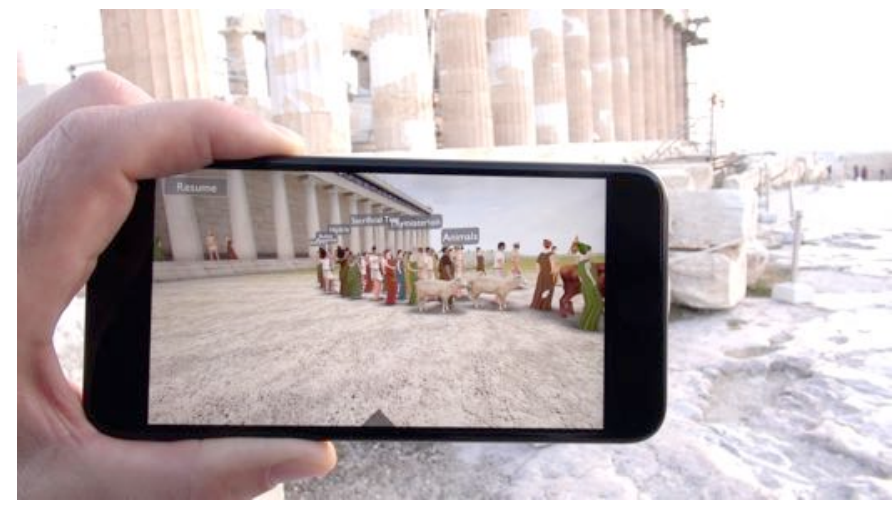

Fig. 5. A touch on the screen surface has halted the temporal sequence and animation and the information layer where spatially positioned hypertext links are visible. Links are attached to moving objects in the procession; animals, humans, instruments etc. The 'Resume' button in the upper left corner ends the pause mode and returns us to the animated sequence mode.

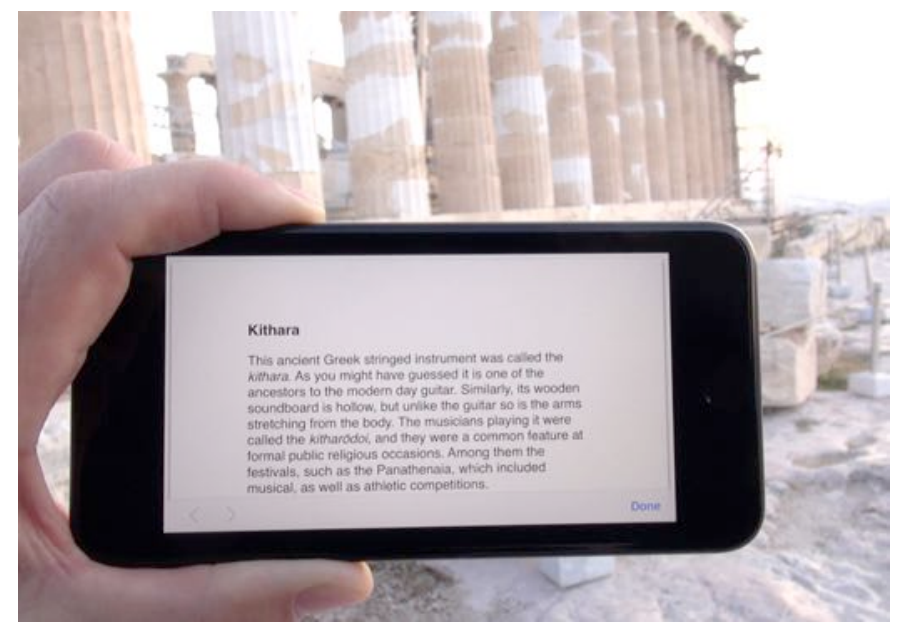

Fig. 6. One of the links attached to the procession is activated and displays a .pdf document with written and pictorial information about one of the ancient string instruments that was used in the procession.

When displaying the Panathenaia procession we decided to focus on the part closest to the Altar of Athena where the procession probably halted while the animals were sacrificed. Thus the movements and animations in the historical event are limited. There is also controversy related to the interpretations of the Panathenaic procession [9]. Following the experiences with this case on the Acropolis we have tested the same functionality in a more recent historical event, and one that is much better documented.

\section{D-DAY ON OMAHA BEACH. RECONSTRUCTING COMPLEX HISTORICAL EVENTS ON LOCATION.}

In the morning of D-Day, June 6th 1944 the allied forces invaded the beaches of Normandy with the largest combined military manoeuvre the world had ever seen. The Germans were well prepared, especially on Omaha Beach where the naval bombardment and bombing from the Allies had minimal 
effect on the well fortified positions. The 'Omaha Beach' sitsim was published for free download on the App Store in June 2017, and reconstructs the first hour of the assault on sectors Easy Red and Fox Green on the eastern part of the beach, near the American Cemetery and Memorial. This reconstruction captures the actions from the naval bombardments started to when the first soldiers reached the limited safety of the shingle bank on top of the beach.

Actions and events on the beach are well recorded. This area is where Robert Capa took his famous photos and Hemingway experienced the attack from a landing craft just off the beach. The historical event is also documented with numerous photos, film clips, maps and last but not least, action reports from the many American soldiers that took part in the assault. Reconstructions of D-Day on Omaha Beach is probably best known today from the opening of Spielberg's movie Saving Private Ryan. A film that, according to many veterans, realistically captures the horrible experience of being there. Despite the fact that Spielberg's reconstruction is true to the memories of the veterans, it is not true to the location and its terrain. The Omaha scene in the movie was shot on location in Ireland at a beach that is much smaller than Omaha, only one fifth of the size of the real terrain (height of the bluffs and width of the tidal falt). When working with location-based media it is not possible to 'lie' about terrain and place, in order to be truthful. The spatial dimensions must be correct and match the real environment in which the simulation is to be used and compared against.

In the Omaha Beach simulation we have drawn on the experiences from both Blücher and Panathenaia. We have compressed the first hour of the battle down to a sequence of about 8 minutes using Genette's categories of 'summary' and 'ellipsis' as guiding design principles. At any point in time the sequence representing the battle can be paused by touching the screen. Although all animation (and thus time) is then on halt, the virtual camera inside the digital environment is operational and the user can reposition him or herself in the simulation by moving in the real environment and thus accessing the available hypertext links for in-depth background information. Photos from user sequence on loation exemplifies this transition, see figures 7-9..

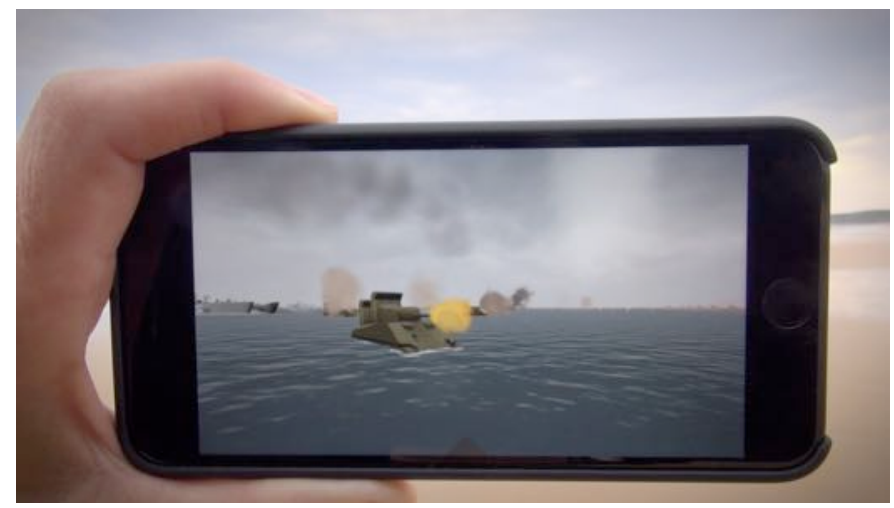

Fig. 7. The user is positioned out on the beach observing the landing of wading Sherman tanks disembarking from LCTs.

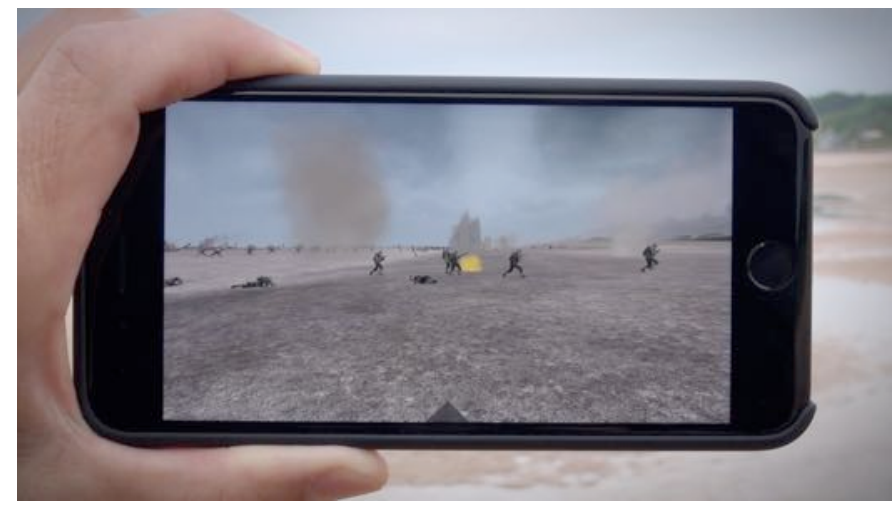

Fig. 8. The user is here positioned closer to the top of the beach observing the first soldiers to reach the limited cover of the shingle bank while under heavy small arms and mortar fire.

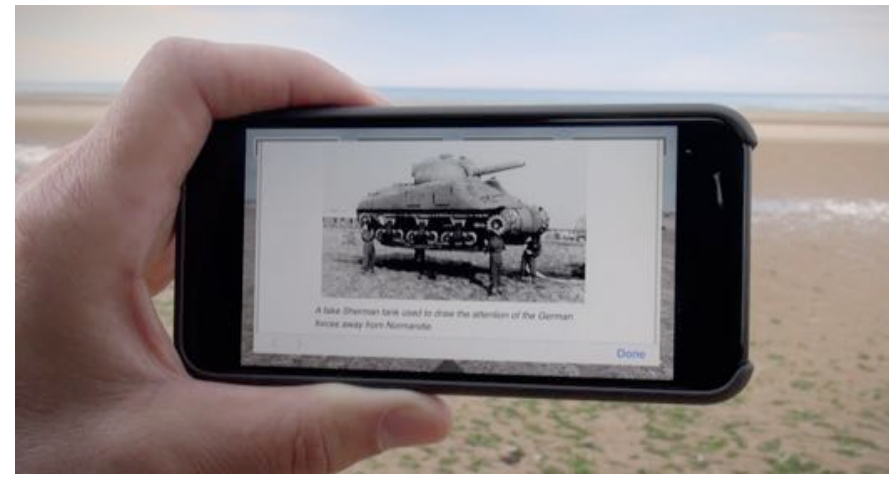

Fig. 9. The user has paused the temporal sequence and accessed a link describing Operation Fortitude, the Allies' attempt at luring the Germans into believing that the invasion would take place near the strait of Calais. The picture shows a decoy Sherman tank made of rubber and filled with air.

\section{TESTING AND USER FEEDBACK.}

Storytelling by means of Mobile Augmented Reality has over the past decade gained increased academic attention [10, $11,12]$

The Panathenaia was tested with visitor participants on the Acropolis. These were of two kinds: five students from an international high school in Athens and eight random visitors recruited on site. The participants were observed during the test and got occasional help if any kind of problem arose. After the testing they answered a written questionnairecovering a multitude of aspects related to the application. The five students put a lot of effort into both the testing and answering the questions, while the other eight participants had less time to spare and did not fully complete the questionnaire, while they engaged enthusiastically with the application. All seven of the of the participants who answered the question directly linked to the relationship between story and access (the sequence displaying the animated event and access to in-depth background information), experienced the transition from one mode to the other as smooth and intuitive. However, three of 
them noted that it was a bit confusing at first but relished the solution once they understood it properly.

In a similar assessment of the Omaha Beach application we wanted to make the distinction between sequence mode and access mode more obvious. This was, among other things, attempted by letting the early part of the sequence be designed like a documentary film based on relevant black and white photos with an audio narration. After a short introductory documentary mode segment, the still photos were replaced by the dynamic $3 \mathrm{D}$ environment, while the audio narration in documentary style continued for the rest of the (interactive) sequence.

The testing with visitor participants on location at Omaha Beach was conducted on two occasions, with different versions of the application. Here we will only report on the final test made just prior to the publication of the app (when the sequence was fully developed). During this trial five visitors (four male, age 25-71, and one female age 41) participated and all answered a short questionnaire consisting of seven questions (due to bad weather and heavy rain the supply of visitors was rather limited). We will focus on two questions particularly relevant to the main topic in this paper:

1. How did you experience the 'pause-to-access' feature? (= touching the screen to stop the story/action/animation, and then access background information.)

\section{Did the digression into the linked information distract or} enrich your experience of the main story?

All the five participants said that they experienced the diversion into the background information as an enhancement or enrichment of the main story. None found it confusing, as had been the case with the Panathenaia simulation. One visitor suggested that we should add verbal info as audio so that one may continue to explore the environment instead of reading the text on the screen. This is an interesting proposal and when we can afford higher resolution objects in the general environment it will certainly make sense. However, some types of information are best on a 2D plane, such as photos, videos, diagrams, maps etc.

All the five participants found the transition between sequence mode and access mode very positive and characterised it in the following ways: 'intuitive', 'easy to use', 'worked very well, great feature to have'. Two of the visitors suggested that we should substitute the 'Back' button (when moving from access mode to sequence mode) with a 'Resume' button. This was complied with in the final published version of the simulation. Overall the testing on location has provided valuable feedback and confirmed that we are on the right track finding a solution to the 'sequence-access paradox'.

After the 'Omaha Beach' simulation was published we have used a logging application to determine if the app is used according to our expectations. To some extent it is, but certain challenges became particularly evident. In the published version we give detailed information about where to start the simulation (the parking lot by the beach below WN62). We also provide an in-app map and directions for how to get there if the app is activated more than $500 \mathrm{~m}$ from the suggested starting position. However, many visitors obviously do not read the guidelines and activate the map in many places closer than $500 \mathrm{~m}$ but still far away from the suggested place to start. As a result they will not experience the simulation as it is intended. They will instead find themselves in a marginal position to where the key activities are going on and where the main information is provided. Remember that we have only reconstructed the actions on a small part of the $7 \mathrm{~km}$ long beach.

In the following screen dump one can see how an active user sequence is recorded according to the tracker app:

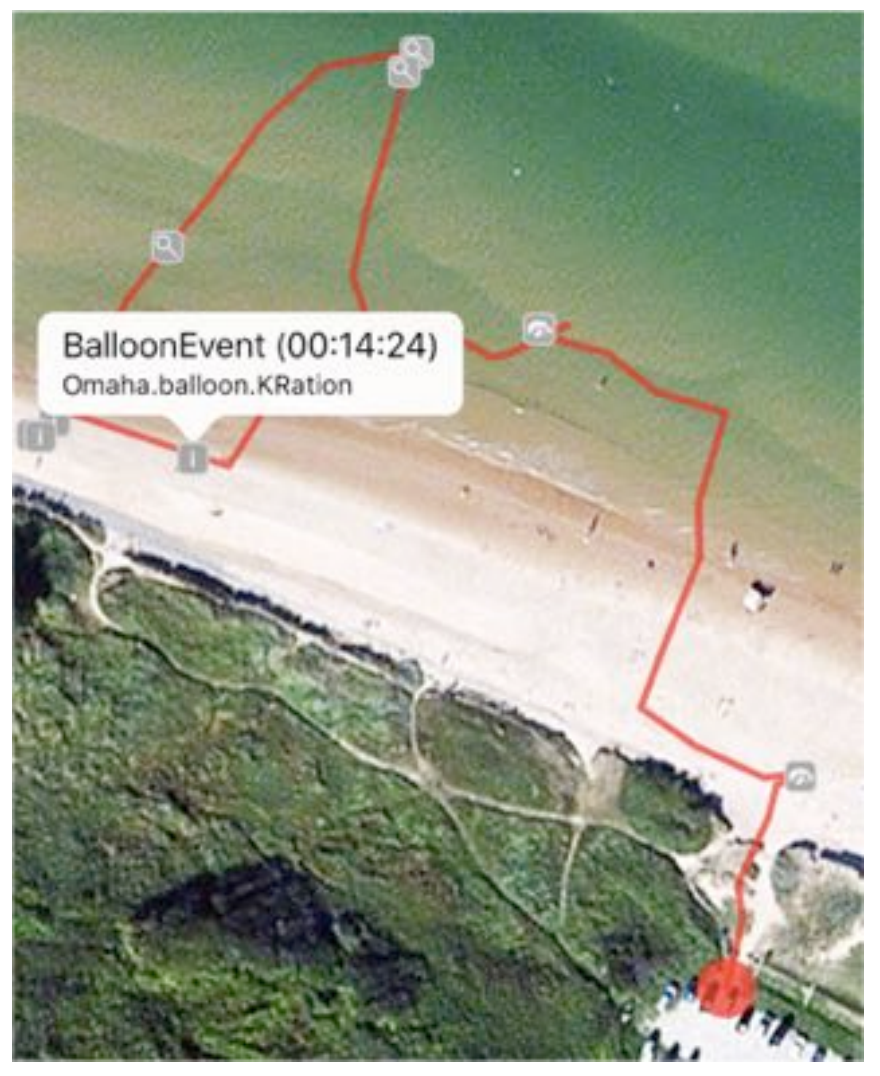

Fig. 10. Screen shot from the Tracker application logging user activity in the Omaha Beach AR app. The red dot indicates the position of the user when the application was activated (parking lot below WN 62). The red line shows the movements of the visitor and the grey icons represents actions the user performs in the app: pausing the sequence, accessing a link etc. When touching the grey icons one gets more details about the event, at what time it happened (since starting the app) etc.

Augmented Reality storytelling is still in its infancy and there is much to explore and learn as the technology improves and our understanding of its narrative potential matures. In future implementation of situated simulations on new locations and updates of existing applications and sites, such as 'Omaha Beach', we will certainly do our best to come up with innovative as well as sustainable solutions. 


\section{ACKNOWLEDGEMENT}

Special thanks to Tomas Stenarson founder of CodeGrind $\mathrm{AB}$, without his programming skills the sitsim platform would not have been possible, at least not in its present shape (he is also the brain behind the Tracker app); and to Sarunas Ledas, Founder of Tag of Joy, for invaluable contribution developing the 3D models and the animations. Thanks also to students at the MEVIT3810 course in the spring of 2016 and 2017 who contributed to the Panathenaia and Omaha prototypes. Thanks to the INREMO-network funded by the Norwegian Research Council, which funded the development and experimentation with the Blücher prototype. The Panathenaia and Omaha systems have been funded by the University of Oslo.

\section{REFERENCES}

[1] Wither, J., Tsai, Y.-T. \& Azuma, R. (2011): Indirect Augmented Reality. Computers \& Graphics 35, 810-822, 2011.

[2] Liestøl, G., Rasmussen, T. \& Stenarson, T. (2011) 'Mobile Innovation: Designing \& Evaluating Situated Simulations' in Digital Creativity 2011, Vol. 22, No. 3, pp. 172-184. Abingdon: Routledge, Taylor \& Francis Group (2011).

[3] Binder, F. \& Schlünz. (1990) Schwerer Kreuzer Blücher. Koehlers Verlagsgesellschaft, Herford.

[4] Genette, G. (1980) Narrative Discourse. An Essay on Method. Ithaca: Cornell University Press.

[5] Liestøl, G. \& Morrison, A. (2013) 'Views, Alignment and Incongruity in Indirect Augmented Reality' in Proceedings of ISMAR 2013, IEEE International Symposium on Mixed and Augmented Reality - Arts, Media and Humanities. 1-4 Oct. 2013, pp 23-28.
[6] Marshall, C. C. and Shipman, I. I. I., Frank M. (1997) 'Spatial hypertext and the practice of information triage'. Proceedings of the eighth ACM conference on Hypertext. pp. 124-133.

[7] Bernstein, M. (2011) 'Can We Talk about Spatial Hypertext?' in Proceedings of Hypertext '11, June 6-9, 2011, Eindhoven, The Netherlands. ACM 978-1-45030256-2, pp. 103-112.

[8] Grønbæk, K., Kristensen, J. F., Ørbæk, P. \& Eriksen, M., A. (2003), "Physical Hypermedia organising collections of mixed physical and digital material. In Proceeding of Hypertext '03. The proceedings of the fourteenth ACM conference on hypertext and hypermedia, Nottingham. New York: ACM, pp. 10-19.

[9] Neils, J. (1997) (ed.) Worshipping Athena: Panathenaia and Parthenon (Wisconsin Studies in Classics), Madison: University of Wisconsin Press, $224 \mathrm{p}$.

[10]Bimber, O., Miquel, L., Schmalsteig, E., D. (2003) 'The Virtual Showcase as a new Platform for Augmented Reality Digital Storytelling, in EGVE '03 Proceedings of the workshop on Virtual Environments, pp. 87-95.

[11]Liestøl, G. (2014) 'Along the Appian Way. Storytelling and Memory across Time and Space in Mobile Augmented Reality', in M. Ioannides et al. (Eds.) Progress in Cultural Heritage: Documentation, Preservation, and Protection. Berlin Heidelberg: Springer Verlag, pp 248-257.

[12] Azuma, R. (2015) 'Location-Based, Mixed and Augmented Reality Storytelling' in Barfield, W. (ed.) Fundamentals of Wearable Computing and Augmented Reality 2nd Edition, CRC Press 2015, pp. 259-276. 